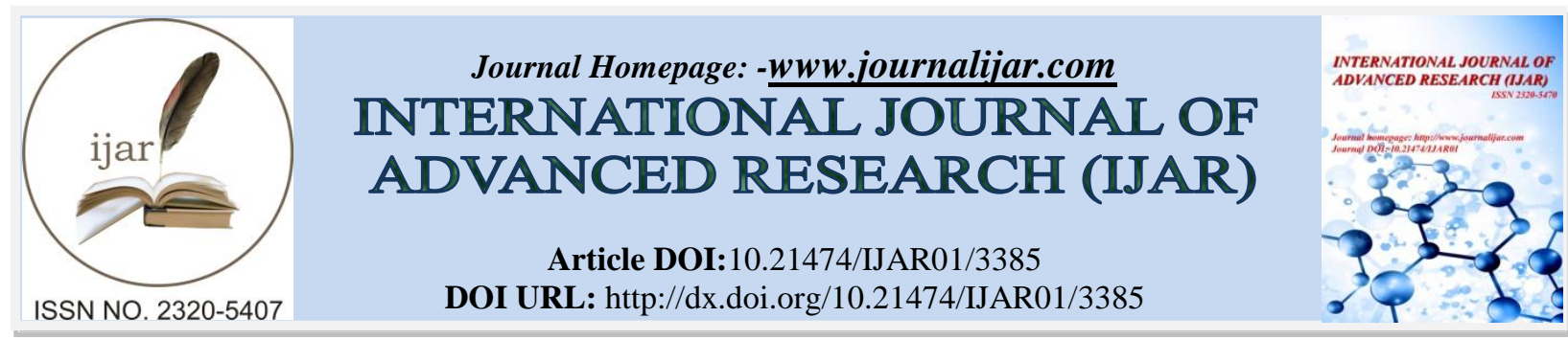

RESEARCH ARTICLE

\title{
PHYSIOLOGICAL, IMMUNOLOGICAL AND HISTOPATHOLOGICAL COMPARISON OF ECHINOCOCCUS GRANULOSUS (G6) CAMEL STRAIN BY DIFFERENT VIABILITY STATUS USING SECONDARY CYST DEVELOPMENT IN RAT
}

\author{
Rasha A. El Sayed ${ }^{1}$, Safaa M. Barghash ${ }^{2}$, Nadia M. El-Alfy ${ }^{1}$, Basma M. Abou-Elnour ${ }^{1}$ and Al- Shaimaa M. \\ Sadek ${ }^{1}$. \\ 1. Department of Zoology, Faculty of Science, Al-Azhar University (Girls), Cairo, Egypt. \\ 2. Parasitology Unit, Animal Health Department, Desert Research Center, Cairo, Egypt.
}

\section{Manuscript Info}

(..........................

Manuscript History

Received: 19 December 2016

Final Accepted: 13 January 2017

Published: February 2017

Key words:-

Echinococcus granulosus, Camels,

Physiology, Immunology,

Histopathology, Egypt.

\section{Abstract}

The current study aimed to demonstrate the differences in hydatid cysts of Echinococcusgranulosus(G6) camel strain by different viability status using secondary cyst development in the rat and to study physiological, immunological and histopathological changes associated with.A comparative study was conducted along time of exposure in different groups of rats which intraperitoneally injected with three different status of the viability of hydatid cyst fluid of camel origin (G6).The groups were:low viability protoscolices (1), high viability protoscolices fluid (2), not viable and not completely transformed to the calcareous status of protoscolices fluid(3), and one negative control group. The immunobiology of host $-E$. granulosus interactions were evaluated by measuring IL-10 a cytokine associated with immunoregulation of effector responses. Histopathological changes were conducted in liver, lung,and kidney because these organs are the target of infection and play an important role in the immune status of the host. Results showed thatthesecondary infection by hydatid cyst fluid in the experimental model causedsevere pathological changes which increased in rats of groups 2 and 3 along with the time of infection, in addition to considerable changes that revealed by hematological and biochemical tests. The median IL-10 level in rats of group 1 was $6.77 \mathrm{pg} / \mathrm{ml}$ compared to $5.74 \mathrm{pg} / \mathrm{ml}$ in control group, while the third group recorded the highest level equal 10.45 (above 10.0 $\mathrm{pg} / \mathrm{ml}$ ). The rats of the second group reached to $9.11 \mathrm{pg} / \mathrm{ml}$, but no more survival of rats above $10.0 \mathrm{pg} / \mathrm{ml}$. Elevated IL-10 levels were correlated with poor survival. We concluded that the most effective stage of hydatid cyst development was the stage before transformation to calcareous phase and the most effective changes in serological, biochemical, immunological and pathological changes occur during this stage.

Copy Right, IJAR, 2017,. All rights reserved. 


\section{Introduction:-}

Cystic echinococcosis is a chronic endemic helminthic disease caused by infection with metacestodes (larval stage) of the tapeworm Echinococcus granulosus. It is one of the most widespread parasitic zoonosisin animals and humans and one of the hygienic complications in both developing and developed countries (Budkeet al., 2006; Carmena et al., 2008; Craig et al., 2007; Menezes da Silva et al., 2010).Hydatid cyst parasitizes many mammals including horses, camels, sheep, cattle, and man, in many organs (Ruedaiet al., 1995) causes severe problems in different animal species especially in animals come in close contact with the final host (Namjoo and Arzanipour,2014).In man, these cysts cause several complaints as pains or heaviness in abdomen and liver, cough, fatigue or anemia, and are often accompanied by hepatomegaly. It can also result in many acute complications such as anaphylactic responses depending on the number and location of the cysts (Ruedaiet al., 1995). Ten strains of $E$. granulosus (G1-10) have been described with molecular biology techniques using mitochondrial DNA sequences (McManus and Thompson, 2003). The sheep strain (G1) and camel strain (G6) have a worldwide geographical distribution, specifically in North Africa, the Middle East and in some European countries (Dakkak, 2010;Khalifaet al., 2014; Varcasiaet al., 2011).Comparative studies on the development of various isolates of the parasite have proved particularly useful, not only for speciation and taxonomy but also in the epidemiology and control of hydatidosis (Smyth \& Davies, 1974; Thompson, 1977; Thompson, 1982).

On hydatid disease two alternative tools have been developed, one is in vitro culture and the other is laboratory animal models (Nakayaet al. 2006; Zak and Sande, 1999). Various species of animals (sheep, baboons, monkey, rabbits, mice, gerbils) and various ways of infection (intragastric administration of eggs, intraperitoneal, intravenous or subcutaneous injection of activated oncospheres and intraperitoneal inoculation of protoscolices or cysts) have been described (Zak and Sande, 1999). In this study, an attempt was made to develop hydatid cysts (G6 genotyping) in rats following intraperitoneal injection of protoscolices (different viability status) and following different changes occurred in rats of different groups along time of the experiment.

\section{Materials and Methods:-}

\section{Collectionof protoscolices:-}

Naturally infected organs (lungs and livers) with hydatid cysts(G6) from camels were collected from El- Bassatein and El-Moneib abattoirs. Cyst fluids were aspirated using sterile disposable syringes and examined for fertility and viability. Cysts which contained no protoscolices (PS), as well as heavily suppurate or calcified, were considered infertile.Fertile cysts were subjected to viability test by centrifugation at 5,000 rpm for 30 min, a drop of the sediment containing the protoscolices was placed on the microscope glass slide and covered with the coverslip and observed for amoeboid-like peristaltic movements (flame-cell activity) with $\times 40$ objective (Salih et al., 2011). When it became doubtful or confusing to observe such movements, a drop of $0.1 \%$ Gentian violet dye solution was added to equal volume of protoscolices in hydatid fluid on a microscopic slide with the principle that viable protoscolices should completely or partially exclude the dye while the dead ones take it up (Macpherson 1985; Smyth and Barrett 1980). Protoscolices were isolated from the fertile cysts washed three times with phosphate buffer saline (PBS $\mathrm{pH}=7.2$ ) and preserved in labeled sterile tubes contain the same volume of warm Hanks' Balarlced Salt Solution (HBSS) for the experiment.

\section{Animals:-}

Seventy-two male albino rats of Sprague Dawelystrain, with average weight 160- $200 \mathrm{~g}$ were obtained from National Research Center, Dokki, Giza, Egypt. Animals were examined to be free from parasitic infection to avoid production of the antibodies before the experiments and kept in Animal house, Faculty of Science, Al-Azhar University, Cairo, Egypt under standard laboratory care of $21^{\circ} \mathrm{C}, 16 \%$ moisture, with water available ad-libitum and diet contains $20 \%$ protein, $3 \%$ fat, and $22 \%$ fiber. Rats were acclimatized for 7 days before the start of the experiment. Animal experiments were carried out according to Institutional Animal Care and Use Committee, National Research Centre Animal Care Unit.

\section{Experiment design:-}

Animals were randomly divided into four groups (18 rats/ each) as follows: the first group intraperitoneally (IP) injected with low viable protoscolices (380 PS in $0.5 \mathrm{ml} \mathrm{HBSS} / \mathrm{rat}$ ), the second group IP injected with high viable protoscolices (1000 PS in $0.5 \mathrm{ml} \mathrm{HBSS} / \mathrm{rat}$ ), the third group injected with $0.5 \mathrm{ml} / \mathrm{rat}$ of semi-calcareous fluid, before completely calcification, and has no protoscolices, whereas the fourth negative control group administrated with only HBSS. After injection, rats daily examined to monitor external and morphological changes for 3 weeks before 
scarifying. Three animals per group were sacrificed at the end of each week from the $3^{\text {rd }}$ to the $8^{\text {th }}$ weeks (6 weeks) post infection for post-mortem examinations. Before scarifying, rats of the second and third groups died earlier at the $7^{\text {th }}$ and $6^{\text {th }}$ weeks respectively.

\section{Blood collection and preparation:-}

Rats were anesthetized using cotton wool soaked in chloroform and the abdominal cavity was opened until the sternum using medical scissors. The blood samples were directly drawn from the heart using $5 \mathrm{ml}$ sterile syringe into clean, dry centrifuge tubes that allowed to stand for 10 minutes at room temperature, then centrifuged at 3000rpm for 15 minutes using laboratory centrifuge (SM 800B, Surgifriend Medicals, England). Sera were carefully removed and stored frozen at $-80^{\circ} \mathrm{C}$ until used for biochemical and immunological analyzes. Blood used for hematological analysis was collected into heparinized sample tubes containing EDTA to prevent the blood from clotting and taken for analyzes within 24 hours of collection.

\section{Hematological studies:-}

Hematological parameters including red blood cells (RBCs), white blood cells (WBCs) and platelets count in addition to hemoglobin level, hematocrit, mean cell hemoglobin (MCH), mean cell hemoglobin concentration $(\mathrm{MCHC})$, mean cell volume (MCV) were accomplished. The samples were analyzed using the automated hematologic analyzer SYSMEX, KX-21 (Japan) as described by Dacie and Lewis, (1991).

\section{Biochemical analysis:-}

Serum samples were analyzed for total protein (Biuret method) (Smith, 1985), albumin (BromoCresol green (BCG) (Doumaset al., 1971), cholesterol (Cholesterol Oxidase/ Peroxidase method) (Allainet al., 1974), Bilirubin (Ballisteri and Shaw, 1987) and glucose (Caraway and Watts, 1987). The activity of liver enzymes Alanine aminotransferase (ALAT), Aspartate aminotransferase (ASAT) was measured by (Gella et al., 1985) method, acid phosphatase (AcP) (Hilman and Klin, 1971), alkaline phosphatase (ALP) (Rosalkiet al., 1993) and Gammaglutamyl-transpeptidase (GGT) by SZASZ method (Orlowski and Meister, 1963). All biochemical parameters were determined using a Technicon RA-2000 random access, automated analyzer.

\section{Measurement of cytokines in serum:-}

Rat IL-10 ELISA kit is an in vitro enzyme-linked immuno-sorbent assay for the quantitative measurement of rat IL10 in serum, plasma, and cell culture supernatants. This assay employs an antibody specific for rat IL-10 coated on a 96-well plate. Standards and samples are pipetted into the wells and IL-10 present in a sample is bound to the wells by the immobilized antibody. The wells are washed and the biotinylated anti-rat IL-10 antibody is added. After washing away unbound biotinylated antibody, HRP- conjugated streptavidin is pipetted to the wells. The wells are again washed, a TMB substrate solution (12 $\mathrm{ml}$ of 3, 3,5,5'- tetra-methyl-benzidine in buffer solution) is added to the wells and color develops in proportion to the amount of IL-10 bound. The stop solution ( $8 \mathrm{ml}$ of $0.2 \mathrm{M}$ Sulfuric acid) changes the color from blue to yellow, and the intensity of the color is measured at $450 \mathrm{~nm}$. The data was calculated by measuring the mean absorbance for each set of duplicate standards, controls, and samples, and subtract the average zero standard optical density. The standard curve was plotted on log-log graph paper or using Sigma plot software, with a standard concentration on the $\mathrm{x}$-axis and absorbance on the $\mathrm{y}$-axis. (RayBio® ELISA Kits).

\section{Histopathological preparation:-}

At the end of each week, as shown earlier, portions of liver, kidney, and lung were washed in saline solution and fixed in $10 \%$ formalin for 24-48 hours at room temperature, embedded in paraffin and sectioned at 4-6 micrometers. Sections stained with haematoxylin-eosin stain using standard histological technique according to Bancroft (1975) for histopathological examination by Olympus BX51 light microscope.

\section{Statistical analysis:-}

The results were expressed as Mean \pm standard deviation (SD) of the mean. The significance difference between means was evaluated by one-way analysis of variance (ANOVA) followed by post hoc test for the comparison of significance using the Statistical Package program(SPSS version 23). Values of $\mathrm{P}<0.05$ were considered as statistically significant. 


\section{Results:- \\ Parasitology Results:-}

The current study revealed several external changes that represented in weight loss, loss of body hair and blindness in the infected groups at the end of the experiment, however, the visual inspection after the autopsy showed different changes as internal bleeding and splenomegaly. Autopsy results detected the appearance of laminated layer stage in livers and kidneys of groups 1, 2 and 3 that started at weeks 7,6 and 3 after injection respectively (Fig.1a,1b) while, protoscolices formation appeared in the last rat of the first group at the end of the experiment. Cysts formation showed in all the infected groups as it appeared at week 7 and 8 in the livers and kidneys of rats in group 1. On the other hand, the second group showed cysts formation in rats'liver at the $7^{\text {th }}$ week of infection, while all rats of group 3 showed a formation of cysts in both kidneys and livers starting from the third week of infection until the death of animals earlier at the $5^{\text {th }}$ week of infection. No cysts formation were observed in other organs along the experiment. Nucleated layer (N. L.), brood capsule (B. C.), and protoscolices formation (P.) stages were reported in kidneys of group 1 at $8^{\text {th }}$ week of the experiment. Also, a smear provoked from hydatid cyst showed hooks (Fig. 1c).

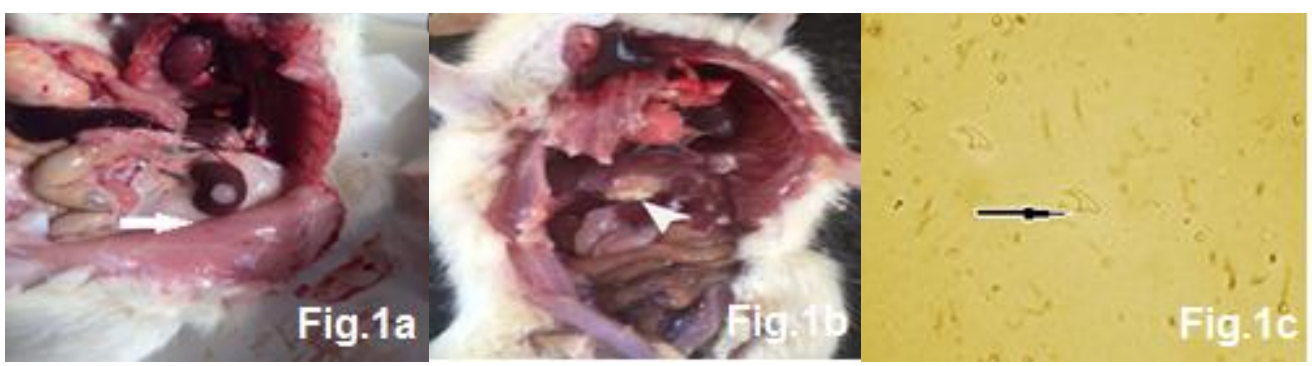

Fig 1:-Showing the four stages in the development of secondary hydatid cysts

\section{Hematological and biochemical results:-}

In the current study, the effect of E.granulosus infection with different viability status on the hematological and serum biochemical parameters was studied for 6 weeks except for groups 3 and 2 where all animals died earlier at the $6^{\text {th }}$ and $7^{\text {th }}$ week of administration was summarized in tables (1) and (2) respectively.

Hematological parameters in the control and E. granulosus infected groups were recorded after 3 weeks of infection at the end of every week revealed that there was a gradual increase in the white blood cells (WBC) along with time in all studied groups as compared to control. On the other hand, the red blood cells (RBC), hemoglobin (HB) and packed cell volume (PCV) were gradually and significantly decreased all over the infected groups in a dose and time-dependent manner as compared to the control. The lowest values were estimated after 8 weeks of infection in the $1^{\text {st }}$ group as all animals in both of group 2 and 3 died at the beginning of the $7^{\text {th }}$ week of infection. Likewise, platelets showed a significant decline all over the infected groups in a time-dependent manner with some fluctuations as compared to the control. Mean corpuscular volume (MCV) recorded increased values in groups 1 and 3 except for group 2 that showed unchanged values until the $6^{\text {th }}$ week of infection where it recorded a significant decrease as compared to the control values. Meanwhile, mean corpuscular hemoglobin concentration (MCHC) exhibited a significant decline in all treated groups at the beginning of the study that restored to be very close to normal at the $4^{\text {th }}$ week except for group 3. Unfortunately, the values could not be followed for both group 2 and 3 as all animals died, but group 1 values showed a continuous decline in MCHC throughout the remaining time of the experiment. However, no significant difference in the mean corpuscular hemoglobin (MCH) between the values of treated groups and those of control was detected (Table 1).

Total protein values showed a significant increase after infection by E. granulosus throughout the experiment as compared to the control (Table 2). Meanwhile, albumin exhibited an insignificant decline in the different infected groups with some fluctuations especially in group 2. Moreover, the average globulin levels recorded a significant elevation that becomes clearly noticed from the $4^{\text {th }}$ week of the experiment with the highest level in the third group as compared to the normal control. Infected rats showed a gradual significant increase in the glucose levels analog with time after exposure to E. granulosus in the different treated groups as compared to control. However, cholesterol levels showed great fluctuations that end in elevation in some groups. Peritoneal administration of $E$. granulosus showed an overall increase in the ASAT and ALAT activities in all groups in a time-dependent manner where the highest levels were obtained after 6 weeks in group 2 as compared to the control. However, E. granulosus infection did not show any significant change in the GGT activities in groups 1 and 2, its activity recorded gradual 
significant increased values in group 3. In addition, group 1 showed a slight increase in GGT values in the last two weeks of the experiment. Furthermore, E.granulosus (G6), camel strain, infected rats showed a marked increase in the levels of serum ALP in comparison with that of control rats as shown in Table (2). No significant difference was detected in AcP levels in group 2, however, its level in group 1 and group 3 showed a gradual significant change that was inversely related to time in group 1 as compared to control. On the other side, the effect of E.granulosus showed an increased trend in bilirubin levels that was more pronounced in group 1 as compared to control.

Table 1:-Hematological parameters of the infected rats with different doses of Echinococcus granulosus as compared to control group.

\begin{tabular}{|c|c|c|c|c|c|c|c|c|c|}
\hline \multicolumn{2}{|c|}{$\begin{array}{l}\text { Week/ } \\
\text { Group }\end{array}$} & RBCs & WBCs & Platelets & HB & MCV & MCH & MCHC & PCV \\
\hline \multirow[t]{4}{*}{3} & C & $8.12 \pm 1$ & $13.8 \pm 1$ & $783 \pm 1$ & $14.8 \pm 0.2$ & $59.2 \pm 0.2$ & $18.2 \pm 1$ & $30.8 \pm .2$ & $48.1 \pm 1$ \\
\hline & G1 & $7.42 \pm 1$ & $12.4 \pm 0.2 *$ & $408 \pm 2 *$ & $12.9 \pm 0.1 *$ & $64.4 \pm 0.1 *$ & $17.4 \pm 0.5$ & $26.9 \pm 0.1 *$ & $47.9 \pm 0.1$ \\
\hline & G2 & $7.11 \pm 2$ & $17.3 \pm 0.3^{*}$ & $490 \pm 3^{*}$ & $12.3 \pm 0.2^{*}$ & $58.4 \pm 1$ & $17.3 \pm 1$ & $29.6 \pm 0.5^{*}$ & $41.5 \pm 0.5 *$ \\
\hline & G3 & $5.97 \pm 0.3$ & $16.9 \pm 0.5^{*}$ & $632 \pm 1^{*}$ & $10.1 \pm 1 *$ & $61 \pm 0.5^{*}$ & $16.9 \pm 0.1$ & $27.7 \pm 0.3^{*}$ & $10.1 \pm 1 *$ \\
\hline \multirow{4}{*}{4} & C & $8.12 \pm 2$ & $13.8 \pm 0.2$ & $783 \pm 2$ & $14.8 \pm 1$ & $59.2 \pm 1$ & $18.2 \pm 2$ & $30.8 \pm 2$ & $48.1 \pm .1$ \\
\hline & G1 & $5.3 \pm 0.2 *$ & $19.8 \pm 0.3^{*}$ & $407 \pm 2^{*}$ & $10.9 \pm 0.1^{*}$ & $69.1 \pm 0.8^{*}$ & $20.4 \pm 2$ & $29.7 \pm 0.3$ & $36.2 \pm 0.2 *$ \\
\hline & G2 & $6.65 \pm 1$ & $17.3 \pm 0.3^{*}$ & $485 \pm 5^{*}$ & $11.3 \pm 0.5^{*}$ & $58.3 \pm 0.2$ & $16.9 \pm 0.6$ & $31.8 \pm 0.2$ & $35.5 \pm 0.5^{*}$ \\
\hline & G3 & $4.3 \pm 0.3^{*}$ & $21.2 \pm 2 *$ & $309 \pm 2 *$ & $9.2 \pm 1 *$ & $74.5 \pm 0.5^{*}$ & $21.2 \pm 2$ & $28.4 \pm 0.4^{*}$ & $9.2 \pm 2 *$ \\
\hline \multirow[t]{4}{*}{5} & $\mathrm{C}$ & $8.1 \pm 0.5$ & $13.8 \pm 1.5$ & $783 \pm 3$ & $14.8 \pm 0.1$ & $59.2 \pm 0.1$ & $18.2 \pm 0.2$ & $30.8 \pm 0.5$ & $48.1 \pm 0.5$ \\
\hline & G1 & $5.1 \pm 0.5^{*}$ & $21.9 \pm 0.1 *$ & $408 \pm 2^{*}$ & $10.4 \pm 0.5^{*}$ & $68.9 \pm 2 *$ & $20.3 \pm 0.2 *$ & $29.4 \pm 1$ & $35.3 \pm 0.3^{*}$ \\
\hline & G2 & $5.98 \pm 1 *$ & $18.3 \pm 2 *$ & $465 \pm 4 *$ & $11 \pm 0.7 *$ & $58.3 \pm 0.2$ & $18.3 \pm 0.5$ & $31.5 \pm 0.5$ & $34.9 \pm 0.1 *$ \\
\hline & G3 & $4.2 \pm 0.1 *$ & $22.3 \pm 0.2 *$ & $300 \pm 6^{*}$ & $8.5 \pm 0.9 *$ & $74.2 \pm 1.2^{*}$ & $20.1 \pm 1 *$ & $29.6 \pm 0.3 *$ & $8.4 \pm 0.5^{*}$ \\
\hline \multirow[t]{3}{*}{6} & C & $8.1 \pm 1.5$ & $13.8 \pm 0.5$ & $783 \pm 2$ & $14.8 \pm 0.5$ & $59.2 \pm 3$ & $18.2 \pm 1.5$ & $30.8 \pm 1$ & $48.1 \pm 0.8$ \\
\hline & G1 & $5.1 \pm 0.1 *$ & $22.7 \pm 2 *$ & $487 \pm 1 *$ & $10 \pm 0.9 *$ & $68.6 \pm 0.3 *$ & $19.6 \pm 0.4$ & $28.6 \pm 1$ & $35 \pm 1 *$ \\
\hline & G2 & $5.6 \pm 0.5^{*}$ & $22 \pm 0.6 *$ & $407 \pm 3 *$ & $10.8 \pm 0.2 *$ & $51.2 \pm 0.3^{*}$ & $16.26 \pm 2$ & $31.8 \pm 0.5$ & $34 \pm 0.6^{*}$ \\
\hline \multirow[t]{2}{*}{7} & C & $8.12 \pm 1$ & $13.8 \pm 2$ & $783 \pm 4$ & $14.8 \pm 2$ & $59.2 \pm 0.5$ & $18.2 \pm 0.3$ & $30.8 \pm 0.9$ & $48.1 \pm 2$ \\
\hline & G1 & $5 \pm 1 *$ & $27 \pm 0.5^{*}$ & $491 \pm 1 *$ & $9.3 \pm 0.5^{*}$ & $69.2 \pm 0.5^{*}$ & $18.6 \pm 1$ & $27.1 \pm 0.1 *$ & $34.3 \pm 2 *$ \\
\hline \multirow[t]{2}{*}{8} & $\mathrm{C}$ & $8.1 \pm 0.6$ & $13.8 \pm 0.8$ & $783 \pm 3$ & $14.8 \pm 1.5$ & $59.2 \pm 2$ & $18.2 \pm 0.8$ & $30.8 \pm 3$ & $48.1 \pm 1.5$ \\
\hline & G1 & $4.9 \pm 0.5^{*}$ & $28 \pm 1^{*}$ & $465 \pm 2 *$ & $8 \pm 2 *$ & $69.8 \pm 0.2 *$ & $16.4 \pm 0.2^{*}$ & $23.5 \pm 0.5^{*}$ & $34 \pm 0.5^{*}$ \\
\hline
\end{tabular}

The values are expressed as mean $\pm \mathrm{SD}$. $* \mathrm{P}<0.05$ level compare with control group. C: control group.

\section{Immunological results:-}

The first signs of immune reaction can be observed with the naked eye in the liver, as the small accumulation of cells and appearance of hydatid cyst, as early as 3 weeks after infection. In the early phase of echinococcosis infection (21 days post infection), the concentrations of IL-10 in the sera of the infected rats of group 1 was the same as that of healthy control rats. However, comparing IL-10 concentration for the other two groups recorded increased levels that reached maximum level in rats of group 3. By progression, in the time of the experiment, we noticed a gradual increase in IL-10 levels (Table 3).We also observed when measured IL-10 levels in serum of infected rats; Group (1) still in low levels by comparison with other groups until the end of the experiment (56 days).Group (2) showed gradually increasing until 42 days after the rest of rats died.Group (3) started by an approximately high level of IL-10 and increased until reached to peak (10.45) in 35 days in the last rat of group 3.

Table 2: - Biochemical parameters of the infected rats with different doses of Echinococcus granulosus as compared to control group.

\begin{tabular}{|l|l|l|l|l|l|l|}
\hline Week & Group & Total protein & Albumin & Globulin & Glucose & Cholesterol \\
\hline \multirow{4}{*}{3} & C & $7.6 \pm 1$ & $4.1 \pm 1$ & $3.5 \pm 0$ & $120 \pm 1$ & $63 \pm 2$ \\
\cline { 2 - 7 } & G1 & $7.47 \pm 0.8$ & $4.5 \pm 0.5$ & $2.97 \pm 0.4$ & $137 \pm 1.1^{*}$ & $62 \pm 1$ \\
\cline { 2 - 7 } & G2 & $8.47 \pm 1.7$ & $3.33 \pm 0.3$ & $5.13 \pm 1.4^{*}$ & $118 \pm 0.4$ & $49.2 \pm 1.5^{*}$ \\
\cline { 2 - 7 } & G3 & $8.37 \pm 0.85$ & $4.6 \pm 0.5$ & $3.77 \pm 0.4$ & $163 \pm 1.5^{*}$ & $35.5 \pm 0.5^{*}$ \\
\hline \multirow{4}{*}{4} & C & $7.6 \pm 0.5$ & $4.1 \pm 0.5$ & $3.5 \pm 0$ & $120 \pm 0.5$ & $63 \pm 1$ \\
\cline { 2 - 7 } & G1 & $9 \pm 1^{*}$ & $4.4 \pm 1$ & $4.6 \pm 0$ & $142 \pm 0.9^{*}$ & $72 \pm 0.2^{*}$ \\
\cline { 2 - 7 } & G2 & $9.3 \pm 0.6^{*}$ & $3 \pm 2$ & $6.3 \pm 1.4^{*}$ & $118 \pm 2$ & $53.2 \pm 0.1^{*}$ \\
\cline { 2 - 7 } & G3 & $9.1 \pm 0.6^{*}$ & $3.84 \pm 0.9$ & $5.3 \pm 0.3^{*}$ & $195 \pm 2^{*}$ & $54 \pm 0.5^{*}$ \\
\hline \multirow{5}{*}{$\mathbf{n}$} & C & $7.6 \pm 2$ & $4.1 \pm 2$ & $3.5 \pm 0$ & $120 \pm 2$ & $63 \pm 0.5$ \\
\cline { 2 - 7 } & G1 & $9.6 \pm 0.5$ & $4 \pm 0.5$ & $5.6 \pm 0^{*}$ & $168 \pm 1^{*}$ & $72.7 \pm 0.2^{*}$ \\
\hline
\end{tabular}




\begin{tabular}{|l|l|l|l|l|l|l|}
\hline & G2 & $10.5 \pm 1.5^{*}$ & $2.57 \pm 0.3$ & $7.9 \pm 1.2^{*}$ & $127 \pm 2.3^{*}$ & $59.16 \pm 1.8^{*}$ \\
\cline { 2 - 7 } & $\mathbf{G 3}$ & $9.2 \pm 0.2$ & $3.6 \pm 0.1$ & $5.6 \pm 0.1^{*}$ & $331 \pm 1 *$ & $59.33 \pm 1.3^{*}$ \\
\hline \multirow{6}{*}{$\mathbf{G}$} & $\mathbf{C}$ & $7.6 \pm 0.1$ & $4.1 \pm 3$ & $3.5 \pm 2.9$ & $120 \pm 0.1$ & $63 \pm 0.1$ \\
\cline { 2 - 7 } & $\mathbf{G 1}$ & $10.53 \pm 1.18^{*}$ & $3.9 \pm 2$ & $6.63 \pm 1.09^{*}$ & $190 \pm 1.1^{*}$ & $72.9 \pm 0.28^{*}$ \\
\cline { 2 - 7 } & $\mathbf{G 2}$ & $11.2 \pm 0.5 *$ & $2.52 \pm 0.5$ & $8.68 \pm 0.03^{*}$ & $148 \pm 0.5^{*}$ & $67.9 \pm 0.9^{*}$ \\
\hline \multirow{2}{*}{$\mathbf{7}$} & $\mathbf{C}$ & $7.6 \pm 3$ & $4.1 \pm 2$ & $3.5 \pm 1$ & $120 \pm 3$ & $63 \pm 3$ \\
\cline { 2 - 7 } & $\mathbf{G 1}$ & $11.3 \pm 0.2^{*}$ & $2.22 \pm 0.2$ & $8.98 \pm 0.03^{*}$ & $210 \pm 0.8^{*}$ & $72.9 \pm 0.28^{*}$ \\
\hline \multirow{2}{*}{$\mathbf{G}$} & $\mathbf{C}$ & $7.6 \pm 1.5$ & $4.1 \pm 2$ & $3.5 \pm 0$ & $120 \pm 1.5$ & $63 \pm 0.6$ \\
\cline { 2 - 7 } & $\mathbf{G 1}$ & $11.3 \pm 0.2^{*}$ & $2.22 \pm 0.2$ & $8.98 \pm 0.03^{*}$ & $241 \pm 1.2^{*}$ & $72.9 \pm 0.28^{*}$ \\
\hline
\end{tabular}

\begin{tabular}{|c|c|c|c|c|c|c|c|}
\hline \multicolumn{2}{|c|}{ Weeks/ Group } & ALP & AcP & ALAT & ASAT & GGT & Bilirubin \\
\hline \multirow[t]{4}{*}{3} & $\mathbf{C}$ & $18.03 \pm 0.15$ & $0.03 \pm 0.01$ & $18 \pm 0.5$ & $72.3 \pm 1.1$ & $8 \pm 2$ & $0.24 \pm 0.01$ \\
\hline & G1 & $32 \pm 1 *$ & $0.9 \pm 0.03 *$ & $32 \pm 1 *$ & $170 \pm 2.2 *$ & $6.6 \pm 0.2$ & $0.45 \pm 0.02 *$ \\
\hline & G2 & $20 \pm 1.5 *$ & $0.02 \pm 0.01$ & $58 \pm 0.8 *$ & $212 \pm 3.4^{*}$ & $10 \pm 1$ & $0.29 \pm 0.02 *$ \\
\hline & G3 & $27 \pm 0.9 *$ & $0.06 \pm 0.02$ & $25 \pm 5^{*}$ & $140.67 \pm 1.5^{*}$ & $17 \pm 0.6^{*}$ & $0.31 \pm 0.03 *$ \\
\hline \multirow{4}{*}{4} & $\mathbf{C}$ & $18.03 \pm 0.5$ & $0.03 \pm 0.0$ & $18 \pm 2$ & $72.3 \pm 1.1$ & $8 \pm 0.5$ & $0.24 \pm 0.01$ \\
\hline & G1 & $34 \pm 2 *$ & $0.7 \pm 0.04 *$ & $33.8 \pm 0.1 *$ & $184 \pm 0.1^{*}$ & $6 \pm 3$ & $0.67 \pm 0.02 *$ \\
\hline & G2 & $22.9 \pm 3 *$ & $0.02 \pm 0.01$ & $58 \pm 0.7 *$ & $380 \pm 2 *$ & $9.3 \pm 0.3$ & $0.3 \pm 0.1$ \\
\hline & G3 & $27 \pm 0.7 *$ & $0.2 \pm 0.05^{*}$ & $48 \pm 2 *$ & $255 \pm 0.5 *$ & $25 \pm 0.8 *$ & $0.35 \pm 0.01 *$ \\
\hline \multirow[t]{4}{*}{5} & $\mathbf{C}$ & $18.03 \pm 0.1$ & $0.03 \pm 0.01$ & $18 \pm 1$ & $72.3 \pm 1.1 *$ & $7.97 \pm 0.65$ & $0.24 \pm 0.01$ \\
\hline & G1 & $26 \pm 0.2 *$ & $0.5 \pm 0.1 *$ & $34 \pm 0.4 *$ & $304 \pm 0.6^{*}$ & $7.0 \pm 0.9$ & $0.32 \pm 0.01 *$ \\
\hline & G2 & $24 \pm 0.3 *$ & $0.04 \pm 0.43$ & $70 \pm 0.1 *$ & $480 \pm 5^{*}$ & $9 \pm 3$ & $0.3 \pm 0.01 *$ \\
\hline & G3 & $29 \pm 0.7 *$ & $0.18 \pm 0.01 *$ & $85 \pm 5^{*}$ & $469.3 \pm 1.5^{*}$ & $26 \pm 0.1 *$ & $0.4 \pm 0.04 *$ \\
\hline \multirow[t]{3}{*}{6} & $\mathbf{C}$ & $18.1 \pm 0.3$ & $0.03 \pm 0.01$ & $18 \pm 5$ & $72.3 \pm 1.1$ & $8 \pm 0.01$ & $0.24 \pm 0.01$ \\
\hline & G1 & $26 \pm 0.2 *$ & $0.5 \pm 0.05 *$ & $36.9 \pm 0.1 *$ & $412 \pm 2.5^{*}$ & $8.6 \pm 0.2$ & $0.54 \pm 0.04 *$ \\
\hline & G2 & $24.3 \pm 0.15^{*}$ & $0.01 \pm 0$ & $90 \pm 0.4^{*}$ & $527 \pm 3 *$ & $8 \pm 1$ & $0.42 \pm 0.03^{*}$ \\
\hline \multirow[t]{2}{*}{7} & $\mathrm{C}$ & $18.1 \pm 0.2$ & $0.03 \pm 0.01$ & $18 \pm 0.4$ & $72.3 \pm 1.1$ & $8 \pm 1$ & $0.24 \pm 0.03$ \\
\hline & G1 & $27 \pm 0.4 *$ & $0.3 \pm 0.03 *$ & $37.8 \pm 0.2 *$ & $409 \pm 5^{*}$ & $10.2 \pm 0.5^{*}$ & $0.43 \pm 0.01 *$ \\
\hline \multirow[t]{2}{*}{8} & $\mathbf{C}$ & $18.1 \pm 0.3$ & $0.03 \pm 0.01$ & $17.7 \pm 1.2$ & $72.3 \pm 1.1$ & $8 \pm 0.4$ & $0.24 \pm 0.2$ \\
\hline & G1 & $27 \pm 1 *$ & $0.3 \pm 0.01 *$ & $38 \pm 2.5^{*}$ & $432 \pm 3.3^{*}$ & $11.0000^{*}$ & $0.28 \pm 0.2$ \\
\hline
\end{tabular}

The values are expressed as mean $\pm \mathrm{SD}$. $* \mathrm{P}<0.05$ level compare with control group. C: control group.

\section{Histopathological results:-}

The present study showed the histopathological changes produced mainly in kidneys, liver and to a lesser extent in lungs of rats which appeared as morphological changes, and also autopsy results showed the presence of hydatid cysts especially in both liver and kidney organs:

Table 3:- The change in Interleukin-10 (pg. /ml) levels in infected rats with different doses of Echinococcus granulosus as compared to control group.

\begin{tabular}{|l|l|l|l|l|}
\hline Groups & Control & G1 & G2 & G3 \\
\hline Week 3 & $5.74 \pm 0.02$ & $5.74 \pm 0.04$ & $6.93 \pm 0.03^{*}$ & $7.64 \pm 0.03^{*}$ \\
\hline Week 4 & $5.74 \pm 0.03$ & $5.89 \pm 0.01^{*}$ & $7.57 \pm 0.05^{*}$ & $8.99 \pm 0.04^{*}$ \\
\hline Week 5 & $5.74 \pm 0.04$ & $6.05 \pm 0.05^{*}$ & $8.08 \pm 0.08^{*}$ & $10.45 \pm 0.04^{*}$ \\
\hline Week 6 & $5.74 \pm 0.05$ & $6.12 \pm 0.06^{*}$ & $9.11 \pm 0.06^{*}$ & ---- \\
\hline Week 7 & $5.74 \pm 0.04$ & $6.45 \pm 0.04^{*}$ & ----- & ---- \\
\hline Week 8 & $5.74 \pm 0.04$ & ----- & ---- \\
\hline
\end{tabular}

The values are expressed as mean $\pm \mathrm{SD}$. $* \mathrm{P}<0.05$ level compare with control group

Liver:-

The histological sections in the liver of rat group3 (21days post-infection) showed focal hepatic necrosis associated with inflammatory cells infiltration as well as apoptosis of hepatocytes in addition to sinusoidal leukocytosis (Fig.2a, b,c). Also the histological sections in the same group but in 28 days post infection showed severe pathological changes which increased with post-infection (Fig.3a).These changes were Kupffer cells activation and small focal hepatic necrosis associated with inflammatory cells in addition to portal infiltration with eosinophils and cystic dilatation of bile duct and fibroplasia in the portal triad around the bile duct (Fig.3b), and at end of experiment the 
liver of the last ratin group 1 showed dissociation of hepatic cords and cytoplasmic Vacuolation of hepatocytes (Fig.3c).

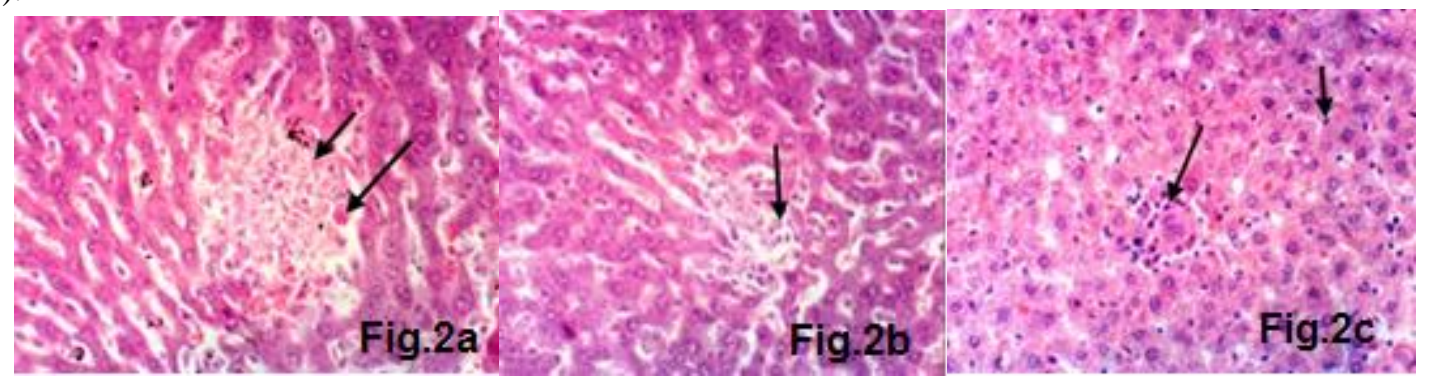

Fig 2:-Sections of rat livers of group 3 after 3 weeks of infection showing focal hepatic necrosis associated with inflammatory cells infiltration as well as apoptosis of hepatocytes (a), sinusoidal leukocytosis (b), and Kupffer cells activation and small focal hepatic necrosis associated with inflammatory cells infiltration (c) (H \& E X 400).

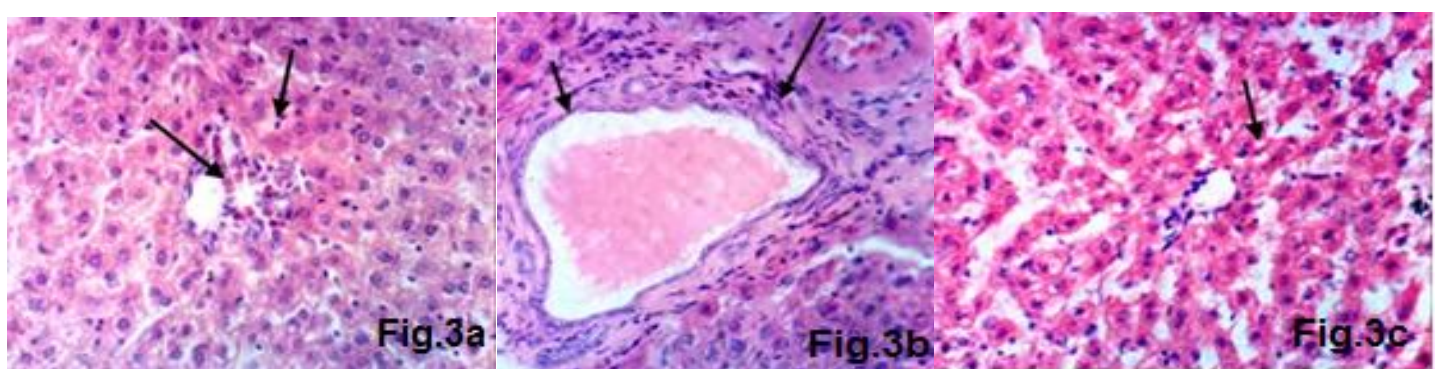

Fig 3:-Sections of rat livers of group 3 after 4 weeks post infection showing Kupffer cells activation and portal infiltration with eosinophil (a), and dilatation of bile duct and fibroplasia in the portal triad around the bile duct (b). Whereas, liver of rat from group 1 in 56 day post infection showing dissociation of hepatic cords and cytoplasmic Vacuolation of hepatocytes (c) (H \& E X 400).

\section{Kidney:-}

The histological sections in the kidney of infected rat groups are demonstrated in Figures 4a-c and 5a-g. Kidney of rats in group1 revealed inflammatory cells infiltration in the renal capsule, atrophy of some glomerular tuft, congestion, and hypertrophy of another glomerular tuft, also results showed hyper-cellularity of glomerular tuft. Histopathological changes which occurred in 5 weeks post infection in the rats of groups $(2 \& 3)$ which increased by increasing the time represented in the eosinophilicproteinaceous material in the lumen of renal tubules.Hypercellularity of the glomerular tuft and the eosinophilicproteinaceous material in the lumen of renal tubules. Thickening of the glomerular basement membrane and focal inflammatory cells infiltration. Vacuolation of tubular epithelium, atrophy of glomerular tuft and distension of Bowman's space. Slight distension of Bowman's space, and thickening of glomerular basement membrane with congestion of glomerular tuft.

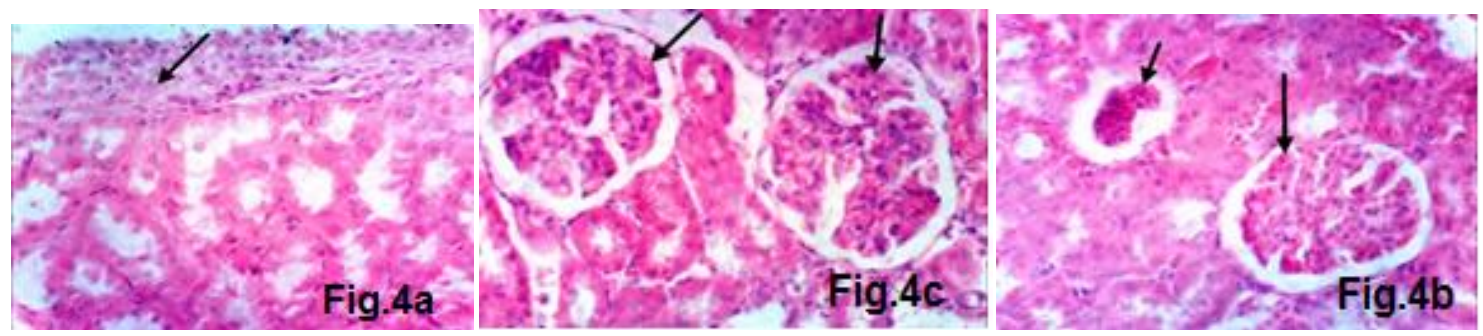

Fig 4:-Sections of rat kidneys of groups $2 \& 3$ after 5 weeks post infection showing inflammatory cells infiltration in the renal capsule (a), atrophy of some glomerular tuft, congestion and hypertrophy of other glomerular tuft (b), and congestion and hypertrophy and hyper-cellularity of glomerular tuft (c) (H \& E X 400). 

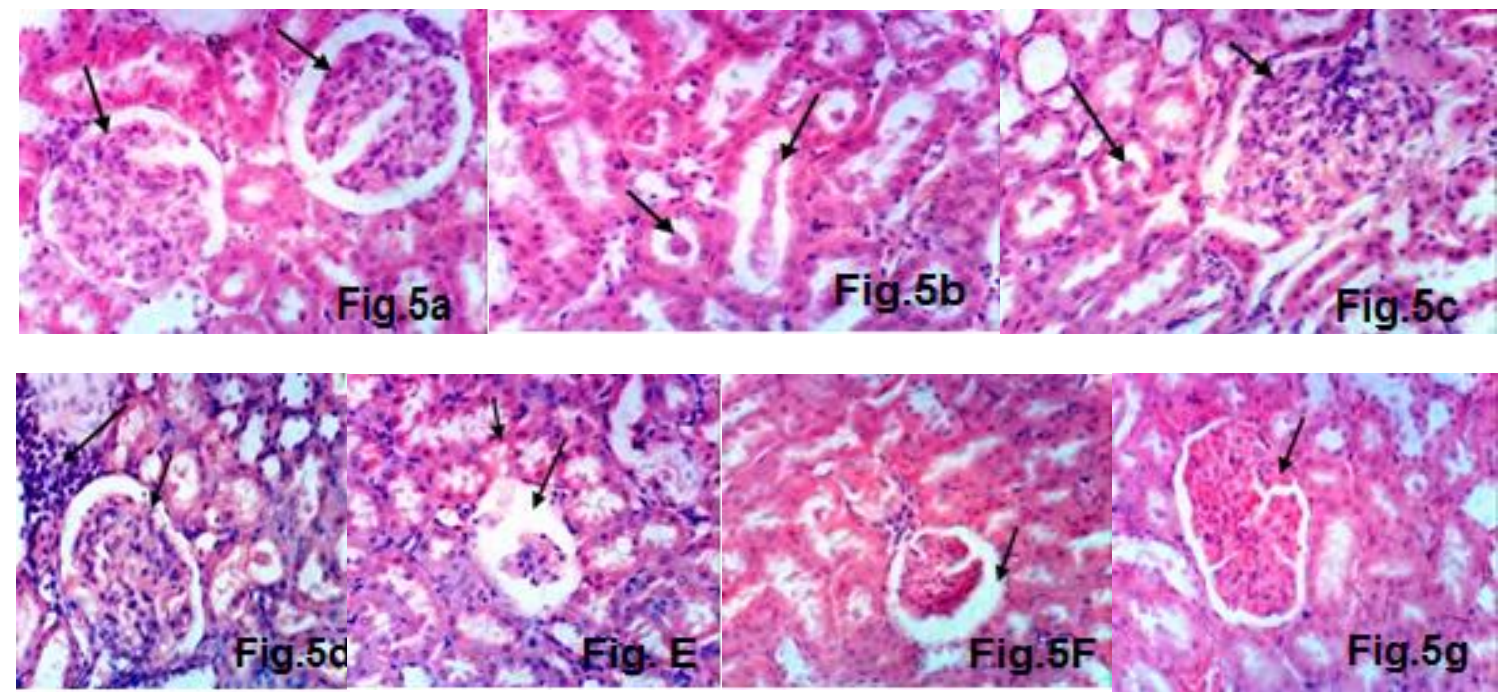

Fig. 5:-Sections of rat kidneys of group 1 after 6 weeks post infection showing hyper-cellularity of glomerular tuft (a), eosinophilic proteinaceous material in the lumen of renal tubules (b, c), thickening of the glomerular basement membrane and focal inflammatory cells infiltration (d), Vacuolation of tubular epithelium, atrophy of glomerular tuft and distension of Bowman's space (e), slight distension of Bowman's space, and thickening of glomerular basement membrane with congestion of glomerular tuft (f).

\section{Lung:-}

Pathological examination of alveolar tissues in the present study revealed that chronic interstitial pneumonia, interstitial pneumonia, and haemosidrosis, in the rat of group 1 in 8 weeks, while the last rat of group 3 at 5 weeks showed the same results in addition to perivasculitis (Fig. 6a-c).

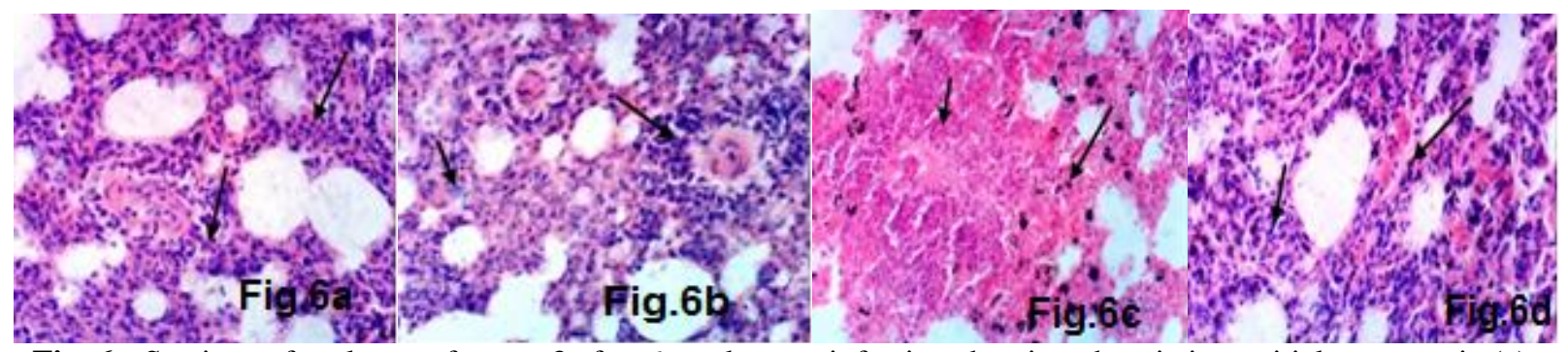

Fig. 6:- Sections of rat lungs of group 3 after 6 weeks post infection showing chronic interstitial pneumonia (a), perivasculitis (b), haemosidrosis (c). Lung of rat from group 1 in 56 day post infection showing chronic interstitial pneumonia and haemosidrosis (d) (H \&E X400).

\section{Discussion:-}

Although the last decade has clarified many aspects of host-parasite relationship in human cystic echinococcosis, establishing the full mechanisms that cause the disease in other intermediate hosts requires more studies(Siracusanoet al., 2012). It is generally accepted thatEchinococcus is unaffected by the immune response during the developing stage. However, natural infections in sheep indicate that some cysts can be killed during the latter stages of development (Zhang and Zhao, 1992), with the relatively frequent occurrence of dead, calcified metacestodes or necrotic cysts.In our experimental study,Hydatid cysts of E. granulosus developed in internal organs (mainly the liver and kidney)of the three group rats as unilocular fluid-filled bladders that consist of two parasite-derived layers, an inner nucleated germinal layer and an outer a cellular laminated layer surrounded by a host-produced fibrous capsule. Brood capsules and protoscolices (PSC) bud off from the germinal membrane. Some cysts indicate enlargement in size, but in some portions active small-cysts takes place. These enlarged cysts have a close relation to brood capsule and scolex formation. In addition, no calcification could be detectedin those lesions growing rapidly along this short cycle in early infection until the end of the experiment. A previous study by Holcman and Heath (1997) showed that secretions from the penetration glands of hatched and activated oncospheres of $E$. granulosus because lysis of host tissues may protect the parasite against the host immune response while the 
laminated layer develops. Another study by Rogan (1988) explained that as the primary cyst having degenerated, leaving the cavity full of host leukocytes and protoscolex-derived daughter cysts. In our opinion, the infection is in progress not in the abortive form of the disease. Moreover, the progression of cyst degeneration does take place in group 3, then 2 and after that group 1 in ascending order may signify increased immunological stimulation with cyst progression. This in contrast to the reports by Wang et al. (2011)that they considered the mild calcification was easy to be detected in those lesions growing rapidly in short cycle.

In the present study, the increasing trend of WBCs may be considered as a defense mechanism against the inflammatory processes which may be produced in the body (especially in the liver) and lead to an increase of WBCs production of the stimulated bone marrow. Likewise, Younuset al., (2016) have been related these changes to the lytic effect of the newly developing E. granulosus hydatid cysts. These results are in agreement with the findings of Al -Nasiri, 2006;Moraitakiet al., 2010; Khalaf, 2013.Previous studies in experimentally induced secondary infections in mice, intraperitoneally injected PSC are surrounded by a considerable cellular infiltration within 3 days, initially involving activated macrophages and subsequently including neutrophils, eosinophils, and lymphocytes ( Richards et al., 1983;Riley et al., 1986; Riley et al., 1985).As far as, red blood cells, platelets, hemoglobin and packed cell volume are usually kept in normal levels through a balance between the new formation and the destruction of old cells in the control group. Our investigation recorded a significant decrease in these parameters which come in a dose and time-dependent mannerthat may be attributed to increased hemolysis or disturbance inthehemopoietin system whichslow of its production (Guyton, 1993). Moreover, Frayha and Haddad, 1980 and Akhtar etal., 1998 related these changes to HCF enzymes that cause an increase in the blood cells destruction. Similar results were obtained from previous studies by Tanveeret al., 1997 and Akhtar et al., 1998 whereas Khalaf, 2013 reported no changes inthese parameter concentrations in rats with E. granulosus.Increased MCV and decreased MCHC that observed in the inoculatedgroups of this study may indicate a macrocytic hypochromic anemiathat cope with the increasing demand of oxygen requirement.The erythrocyte enlargement may be related to an accumulation of fluids after disturbance of cell membrane permeability. Similar findings have also beenpreviously reported (Akhtar et al., 1998;Xhemollariet al., 2016).

Determination of plasma proteins reported having significant prognostic and diagnostic values, especially in liver diseases. Results of the present study revealeda marked increase inserum total protein that may be imputed to increasedrelease of tissue specific enzymes and other intracellularproteins secondary to parasite-induced cell membranedisruption (Orhue and Nwanze, 2004).Similar findings have been reported by Tanveeret al. (1997) andRadfar and Iranyar (2004) but they attributed this increase in protein to incoming CHCF that already contained different kinds of proteins. Ruedaietal., 1995 and Anwar and Tanveer, 2000 interpretedthis elevation in protein concentration with time by the formation of antibodies against antigens present in hydatid cyst fluid (HCF). In agreement with this, our findings revealed a statistically significant elevation in globulins. As far as serum globulins were concerned, several reports determined its alterations with various parasites and revealed its increase specifically in the endoparasites infectionAyazet al., 2007; Dede et al., 2014).On the other hand, our results disagree with those reported by Smyth (1979) and Meduriet al. (1990) that reported a decline in protein level and related this to its use by the parasite, since the protoscolices of E. granulosus can digest host proteins.A drop in albumin levelswas determined in our results in spite of there were no statistical difference as compared to control that may be attributed to the long half-life of albumin,therefore, a decrease in serum albumin is usually not apparent early in the course of liver diseases (Halstedand Halsted, 1981;Cheesbrough, 1998).This hypoalbuminemia may imply a combination of impaired synthesis and loss via the gut, kidney or both as revealed by several studies in various parasite diseases(Yeruhamet al., 1998, Turgut, 2000;Zygneret al., 2007).

Our biochemical results revealed a marked increase in glucose in the experimentally infected animals that may be due to the effect of the infection on the liver which play an important role in the glucose metabolism (Khalaf, 2013) or occurrence of glycolysis and gluconeogenesis cycles which related to energy production within parasite cyst(ElBayatietal., 2010). This in accordance with Shaafieetal., 1999 and Muhsinetal., 2015 who recorded high levels of glucose in the primary intermediate host. As far as the activity of enzymes is concerned, ALP, ALAT and ASAT activities were also measured showed an increase among the treated groups compared to the negative control group.Several studies have also previously reported significant increases in ALP, ALAT, and ASAT activities in E.granulosus infected animals (Abdulla, 2007; Shindalaet al., 2007). These studies explained that the liver infection with Cestodes tapeworms led to hepatocyte destruction and enzyme release or even indicates a cellular response. On the other hand, AcP values were closely related to the control values at the beginning of the experiment then trend to decrease with time. Rahmanet al. (1992) suggested that the decrease in the activities of AcP might be due to the 
increased permeability of plasma membrane or cellular necrosis that showing the stress condition of the treated animals.Taken together, the serum total bilirubin concentrations were dramatically increased in E.granulosus infected groups that may be related to additional enzymes produced by the protoscolices and/ or brood capsule (Anwar and Tanveer, 2000). Increased quantity of total bilirubin also may indicate the increased breakdown of hemoglobin that interprets the decreasing levels in hemoglobin and RBCs levels of our investigation.

During cystic echinococcosis (CE) the host-parasite relationship is interactive and the outcome of infection depends on the balance achieved by the combination of the different variables involved with the host immunity and the $E$. granulosus avoidance strategies (Siracusanoet al., 2008). There is no direct evidence that the viability, death or calcified of such cysts is due to an immunological phenomenon, but it is a likely possibility. In addition, there are no detailed studies of immunological events associated with the degeneration of different types of the cyst, and it is, therefore, unknown which mechanisms may be involved. Our experimental study in rat supported the possible local immunosuppression mediated by IL-10 as a possible mechanism that helps the parasite in escaping the host cellmediated response in agree withMondragón-De-La-Peña et al.(2002).

The co-expression of IL-10 and IFN- $\gamma$ at high levels in human hydatidosis suggests that the immune response to $E$. granulosus infection may be due to the very complex mixture of antigens in hydatid cyst fluid(McManus and Bryant, 1995) which probably contain distinct epitopes for each T-cell subset.Like other helminthic infections (Finkelmanet al., 1991; Lange,et al., 1994; Pearceet al., 1991), echinococcosis induces two very distinct Th1 and Th2 cytokine secretion patterns. It is not understood why hydatid infection can induce high levels of both Th1 (produce IL-2, IFN- $\gamma$, and lymphotoxin), and Th2 cytokines (express IL-4, IL-5, IL-6, IL-10) since they usually down-regulate each other (Pearce et al; 1991).In our results, elevated levels of IL-10 that produced in vivo experimental infectionwere correlated with poor survival in rats and accompanied with severe pathological changes which increased in rats of high and calcareous groups and period post-infection.This is in agreement with Haralabidis et al. (1995) who reported that primary and secondary infections elicit similar responses, which include elevated levels of IL-10. And the increased production of IL-10 in hydatid disease patients corresponds to high levels of IgE (Babbaet al., 1994).

\section{Conclusion:-}

The effective stage of hydatid cyst development was the stage before transformation to calcareous stage. The most effective changes in serological, biochemical, immunological and pathological changes occur during this stage. Secondary infections by hydatid cyst fluid in experimental rats caused an alteration in liver functions in addition to changes in blood and body chemistry which showed by hematological and biochemical tests. Elevated IL-10 levels were correlated with poor survival in rats. Microscopically examination of livers and lungs of animals of different groups showed severe pathological changes which increased in rats of low and calcareous groups and period postinfection. The change of physiological parameters could be considered as a good diagnostic and reliable indicator to monitor the progress and severity of E. granulosus infection.

\section{Ethical approval:-}

All applicable international, national, and/or institutional guidelines for the care and use of animals were followed.

\section{Conflict of Interests:-}

The authors declare that they have no conflict of interests regarding the publication of this paper

\section{Acknowledgement:-}

The authors gratefully acknowledge the financial support from Faculty of Science, Al-Azhar University (Girls), Cairo, Egypt. This work was also supported by Desert Research Center (DRC), Cairo, Egypt.

\section{References:-}

1. Abdullah, B.H. (2007). Some Helminthes Parasitized on Stray Cats Feliscatus L. in Basrah and Epizootiological and Biological Studies on TaeniataeniaeformiBatsch, 1786, Ph.D. Thesis, College of Education, University of Basrah, (In Arabic).

2. Aboelhadid S. M., El-Dakhlya, k., Tokuma, Y., Fukushi, H.,Hassanin, K. (2013). Molecular characterization of Echinococcus granulosus in Egyptian donkeys. Vet Parasitol. 193: 292- 296. 
3. Akhtar, T., Mubashra, T. and Anwar, Z. (1998). Haematological and biochemical changes in rabbits due to high doses of crude hydatid cyst fluid of sheep origin. Pakistan Vet J. 18 (2): 82-86.

4. Al- Nasiri, F.S. (2006). Biological and immunological study of hydatid cyst formation in albino mice. Ph.D. Thesis, College of Education, University of Baghdad, (In Arabic).

5. Allain, C., Poon, L., Chan, C., Richmond, W. and Fu, P. (1974). Enzymatic determination of total serum cholesterol. ClinChim. 20: 470- 475.

6. Anwar, Z. and Tanveer, A. (2000). Blood biochemistry of rabbits after intravenous inoculation of unilocular hydatid cyst fluid of sheep origin. Punjab Univ J Zool. 15: 137- 149.

7. Ayaz, E., Ertekin, A., Özdal, N. and Taş, Z. (2007). Fasciola spp., Dicrocoeliumdendriticum, Kist Hidatik, TrichostrongylidaeveProtostrongylidaeKoyunlardaBazıBiyokimyasalParametreler. TürkiyeParazitolojiDergisi. 30 (4): 57-61.

8. Babba, H., Messedi, A., Masmoudi, S., Zribi, M., Grillot, R., Ambriose-Thomas, P., Beyrouti, I. and Sahnoun, Y.(1994). Diagnosis of human hydatidosis: comparison between imagery and six serologic techniques. Am J Trop Med Hyg. 50:64-68.

9. Balistreri, W. and Shaw, L. (1987). Liver function: Fundamentals of clinical chemistry. $3^{\text {rd }}$ ed. Philadelphia, 729-761.

10. Bancroft, J .D. (1975). Histochemical techniques. 2nd, Butter worthies, London and Boston.

11. Bayati, S., Aziz, O., Abdulla, A. and Abed, S. (2010). Biochemical profile of hydatid cyst fluids of Echinococcus granulosus of sheep in Duhok area. Iraqi J Vet Med. 34 (1): 78-83.

12. Benjamin, M. (1985). Online of veterinary clinical parasitology. $1^{\text {st }}$ edition. Oxford University Press 38-162.

13. Budke, C.M., Deplazes, P. and Torgerson, P.R. (2006). Global socioeconomic impact of cysticechinococcosis. EmergInfect Dis. 12(2): 296-303.

14. Caraway, W. and Watts, N. (1987). Carbohydrates in fundamentals of clinical chemistry. 3ry ed. Philadelphia, 422-447.

15. Carmena, D., Sánchez-Serrano, L. P. andBarbero-Martínez, I. (2008). Echinococcus granulosus infection in Spain. Zoonoses and Public Health 55(3):156-165.

16. Cheesbrough, M. (1998). District laboratory practice in tropical countries part 1.Cambridge University press, Cambridge 1: 355-358.

17. Craig, P.S., McManus, D.P., Lightowlers, M.W., Chabalgoity, J.A., Garcia, H.H., Gavidia, C.M., Gilman, R.H., Gonzalez, A.E., Lorca, M., Naquira, C., Nieto, A. and Schantz, P.M. (2007). Prevention and control of cystic echinococcosis. Lancet Infect Dis. 7:385-394.

18. Dacie, J. V. and Lewis, S. M. (1991). Practical Haematology. Churchill Livingstone. Edinburgh 7: 521 - 534.

19. Dakkak, A. (2010). Echinococcosis/hydatidosis: a severe threat in Mediterranean countries. Vet Parasitol. 174(1-2): 2-11.

20. Dede, S., Altuğ, N., Değer, Y., Özdal, N. and Ceylan, E. (2014). Serum biochemical profile and protein fractions in cattle with Theileriosis. Revue MédVét. 165 (56): 137-143.

21. Doumas, B.,Waston, W. and Biggs, H. (1971). Albumin standard and measurement of serum albumin with bromocresol green. ClinChimActa. 31: 87- 96.

22. El-Kattan, A.M. (2012). Some studies on hydatidosis in camels. Ph. D. V. Sc. Thesis Infectious Diseases. Fac. Vet. Med. Cairo University, Egypt.

23. Finkelman, F.D., Pearce, J.F., Urban, J.R., and A. Sher. (1991). Regulation and biological function of helminthinduced cytokine responses. Immunol Today12:A62-A66.

24. Frayha, G.J. and Haddad, P. (1980). Comparative chemical composition of protoscoleces and hydatid cyst fluid of Echinococcus granulosus. Int J Parasitol. 10: 359.

25. Gella, F., Olivella, T., Cruz, M., Arenas, J., Durban, R. andComez, A. (1985). A simple procedure for routine determination of aspartate aminotransferase and alanine aminotransferase with pyridoxal phosphate. ClinChemActa. 153: 241- 247.

26. Guyton, A. C. (1993). Textbook of Medical Physiology. 9" ed. W.B. Saunders Co., Philadelphia.

27. Halsted, J.A. and Halsted, C.H. (1991). The laboratory in clinical medicine: Interpretation and application. Saunders Company, Philadelphia 2: 281-283.

28. Haralabidis, S., Karagouni, E., Frydas, S. and Dotsika, E. (1995). Immunoglobulin and cytokine profile in murine secondary hydatidosis. Parasite Immunol. 17:625-630.

29. Hillman, G. (1971). Continuous photometric measurement of prostrate acid phosphatase activity. Z KlinChemKlinBiochem. 9:273.

30. Holcman, B. and Heath, D.D. (1997). The early stages of Echinococcus granulosus development. Acta Trop. 64:5-17. 
31. Khalaf, A. (2013). Effects of hydatid cyst infection on some biochemical and haematological parameters in experimental mice Balb/c strain. J College of Edu pure sci. 3(2): 1-9.

32. Khalifa, N.o., Khater, H.F., Fahmy, H.A., Radwan,M.E. and Afify, J.S.A. (2014). Genotyping and phylogenetic analysis of cystic echinococcosis isolated from camels and humans in Egypt. Amer J EpidInfect Dis. 2.3 (2014): 74-82.

33. Lange, A. M., Yutanawiboonchai, W., Scott, P. and Abraham, D. (1994). IL-4- and IL-5-dependent protective immunity to Onchocerca volvulus infective larvae in BALB/c BYJ mice. J Immunol. 153:205-211.

34. Macpherson, C. N. (1985). Echinococcosis a plague on pastoralist. In Parasitic Helminths and Zoonosis in Africa. 2: 25- 53.

35. McManus, D. P. and Bryant, C. (1995). Biochemistry, physiology and molecular biology of Echinococcus, p. 355-410. In R. C. A Thompson and A. J. Lymbery (ed.), The biology of Echinococcus and hydatid disease. CAB International, Wallingford, United Kingdom.

36. McManus, D. P. and Thompson, R. C. A. (2003). Molecular epidemiology of cystic echinococcosis. Parasitol. 127: S37-S51.

37. Meduri, A., Lovane, A., Martone, A., Bonaduces, S. and Palomba, E. (1990). Sialic acid, mucoproteins and phospholipids in serum of healthy cattle with echinococcosis, and in hydatid fluid. Acta Medical Vet. 36(2): 151-166.

38. Menezes da Silva, A. (2010). Human echinococcosis: a neglected disease. Gastroenterology Research and Practicehttp://dx.doi.org/10.1155/2010/583297

39. Mondragón-De-La-Peña, C., Ramos-Solís, S., Barbosa-Cisneros, O., Rodríguez-Padilla, C., Tavizón-García, P. and Herrera-Esparza, R. (2002). Echinococcus granulosus down regulates the hepatic expression of inflammatory cytokines IL-6 and TNF $\alpha$ in BALB/c mice. Parasite 9(4): 351-356.

40. Moraitaki, P., Roussi, P., Emmanouil, Y., Pechlivanidou, R., Bitsakou, C., Konstantinou, M. and Marosis, K. (2010). Pulmonary echinococcosis presenting as a pulmonary mass with fever and haemoptysis; a case report. Pneumon. J. 23(2): 180 - 183.

41. Muhsin, S., Ahmed, D. and Hassan, A. (2015). Hydatid cyst fluid of Echinococcus granulosus isolated from infected Human, sheep and cattle in Baghdad. J Nursing Health Sci. 4 (6):72-74.

42. Nakaya, K., Mamuti, W., Xiao, N., Sato, M.O., Wandra, T.,Nakao, M., Sako, Y., Yamasaki, H., Ishikawa, Y., Craig,P.S., Schantz, P.M. and Ito, A. (2006). Usefulness of severe combined immunodeficiency (scid) and inbred mice for studies of cysticercosis and echinococcosis. Parasitol Int. 55: 91-97.

43. Namjoo, A. and Arzanipour, N. (2014). Serum liver enzymes profiles of cattle infected with hydatid cyst at Shahrekord abattoir in ChaharmahalVaBakhtiari Province, Iran. Int J Biosci. 4 (1): $469-476$.

44. Orhue, N.E.J. andNwanze, E.A.C. (2004). Effect of Scopariadulcis on Trypoanosomabrucei induced alterations in serum transaminase, alkaline phosphatase and bilirubin in the rabbit. J Med Sci. 4(3): 194- 197.

45. Orlowski, M. andMeister, A. (1963). Gamma-glutamyl-p-nitroanilide: a new convenient substrate for determination and study of 1- and d-gamma-glutamyltranspeptidase activities. BiochimBiophys Acta.73(6): 679681.

46. Pearce, E. J., Caspar, P., Grzych, J.M., Lewis, F.A. and Sher, A. (1991). Down regulation of Th1 cytokine production accompanies induction of Th2 responses by a parasitic helminth, Schistosoma mansoni. J Exp Med. 173:159-166.

47. Radfar, M., Tajalli, S. and Alipour, T. (2012). Comparative study of cattle, sheep and goats on biochemical profiles of hydatid cyst fluid from the lungs and liver. Comp ClinPathol. 21: 1135-1137.

48. Rahman, M.S., Sokar,S. and Dahab, S. (1992). Comparative studies on hydatidosis in farm animals in Egypt. DtschTierarztlWochenschr 99: 438-440.

49. Rogan, M.T. (1988). Observations on the origin of daughter cysts within hydatid cysts of Echinococcus granulosus. Ann Trop Med Parasitol. 82:405-406.

50. Richards, K. S., Arme, C. and Bridges, J.F. (1983). Echinococcus granulosus equinus: an ultrastructural study of murine tissue response to hydatid cysts. Parasitol. 86:407-417.

51. Riley, E. M., Dixon, J. B., Jenkins, P. and Ross, G. (1986). Echinococcus granulosus infection in mice: host responses during primary and secondary infection. Parasitol. 92:391-403.

52. Riley, E.M., Dixon, J.B., Kelly, D.F. and Cox, D.A. (1985). The immune response to Echinococcus granulosus: sequential histological observations of lymphoreticular and connective tissues during early murine infection. J Comp Pathol. 95:93-104.

53. Rosalki, S., Foo, A. and Burlina, A. (1993). Multicenter evolution of iso- ALP test kit for measurement of bone alkaline phosphatase activity in serum and plasma. Clin Chem. 39: 648- 652. 
54. Ruedai, M., Osunaz, A., Derycke, P. and Janssen, D. (1995). Biochemical evaluation of mice, experimentally infected with Echinococcus granulosus metacestodes. Res Rev ill Parasitol. 55 (2): 109-111

55. Salih, M., Hailu, D. and MotiYohannes, M. (2011). Infection rates, cyst fertility and larval viability of hydatid disease in camels (Camelusdromedarius) from Borena, Kereyu and Harare areas of Ethiopia. Global Vet. 7(6): 518-522.

56. Shaafie, A., Khan, A.H. and Rambabu, K. (1999). Biochemical profiles of hydatid cyst fluids of Echinococcus granulosus of human and animal origin in Libya. J Helminthol. 73(3): 255-263.

57. Sharif, M., Keighobadi, M., Ziaee, H., Izadi, J., Gholami, S.H. and Khalilian A. (2004). Measurement of biochemical components of liver Hydatid cyst fluids in human, sheep, goat, cattle and camel. Mazandaran J Arak Uni Med Sci. 2: 24-31.

58. Shindala, N. A., Al-Kassim, K. H., Shabaan, E. K., Shehab, A. K., Husain, A. K. and Alias, H. Y. (2007). Study the toxic effect of albendazole excretion in the milk on the sucking pups. The 4th Scientific Conference. College of Veterinary Medicine, Mosul University 1:177-188.

59. Siracusano, A., Rigano, R., Ortona, E., Profumo, E., Margutti, P., Buttari, B., Delunardo, F. and Teggi, A. (2008). Immunomodulatory mechanisms during Echinococcus granulosus infection. ExpParasitol. 119:483489.

60. Siracusano, A., Delunardo, F., Teggi, A. and Ortona, E. (2012). Host-Parasite Relationship in Cystic Echinococcosis: An evolving story clinical and developmental immunology. http://dx.doi.org/10.1155/2012/639362.

61. Smith, P.K. (1985). Measurement of protein using bicinchoninicacid.Anal Biochem. 150, 76-85.

62. Smyth, J. D. (1979). Echinococcus granulosus and E. multilocularis: in vitro culture of strobilar stage from protoscolices. AngewParasit. 20:137-147.

63. Smyth, J. and Barrett, N.J. (1980). Procedure for testing the viability of human hydatid cyst following surgical removal, especially after chemotherapy. Trans Royal Soc Trop Med Hyg. 74: 649-652.

64. Smyth, J. and Davies, Z. (1974). In vitro culture of the strobilar stage of Echinococcus granulosus (sheep strain): A review of basic problems and results. Int J Parasitol. 4(6): 631-644.

65. Tanveer, A., Ahmad, W. and Anwar, Z. (1997). Effect of low doses of filtered hydatid cyst fluid on some blood and liver function tests in rabbits. Biologia. 43:169-181.

66. Thompson, R. C. A. (1977). Biology and Systematic of Echinococcus In "Biology of Echinococcus and Hydatid disease". George Allen and Unwin, London 4: 52.

67. Thompson, R. C. A. (1976). Biology and Systematics of Echinococcus. The Biology of Echinococcus and Hydatid Disease. Ed. Unwin, London 5: 43.

68. Thompson, R. C. A. (1982). Biology and Systematic of Echinococcus and Hydatid disease. CAB International Wallingford, Oxen 1:37.

69. Turgut, M. (2000). Hydatid disease of the spine: A survey study from Turkey. Inf. 25: 221-226.

70. Varcasia, A. Tanda, B., Giobbe, M., Solinas, C., Pipia, A.P., and Malgor, R. (2011). Cystic echinococcosis in Sardinia: farmers' knowledge and dog infection in sheep farms. Vet Parasitol. 181(2): 335-340.

71. Wang, J., Xing, Y., Ren, B., Xie, W.D., Wen, H. and Liu, W.Y. (2011). Alveolar echinococcosis: correlation of imaging type with PNM stage and diameter of lesions. Chin Med J. 124 (18): 2824-2828.

72. Xhemollari, E., Dhaskali, L., Papaioannou, N. and Kritsepi M. (2016). Evaluation of hematological and biochemical indicators by pathologies. The 4th Global Virtual Conference, 314-318.

73. Yarsan, E., Altinsaat, C., Aycicek, H.,Sanindokuyucu, F. and Kalkan, F. (2003). Effect of albendazole treatment on hematological and biochemical parameters in healthy and Toxocaracanis infected mice. Turk J Vet Anim Sci. 27: 105- 117.

74. Yeruham, I.,Hadani, A., Galker, F., Avidar ,Y. andBogin, E. (1998). Clinical, clinico-pathological and serological studies of Babesiaovis in experimentally infected sheep. ZentralblVeterinarmed B. 45(7): 385-394.

75. Younus, M., Muhammad, M., Khan, A., Akhtar, T. and Akhtar, M. (2016). Hematological changes in the hydatidosedmale sheep after experimental inoculation of Echinococcus granulosus Eggs. Int J Agri Biosystems Eng. 3(1).

76. Zak, O. and Sande, M.A. (1999). Hand book of animal models of infection. England 1:142-170.

77. Zhang, W. B. and D. Z. Zhao. (1992). A comparison of calcification of hydatid cysts in sheep pastured and post-fed. Chin J Vet Sci Technol. 22:28-29.

78. Zygner, W., Gojska, O., Rapacka, G., Jaros, D. and Wedrychowicz, H. (2007). Hematological changes during the course of canine babesiosis caused by large Babesia in domestic dogs in Warsaw (Poland). Vet Parasitol. 145:146-151. 